\title{
RELATÓRIO SOBRE A MARCHA E ESTADO DA ESCOLA PRIMÁRIA NEUTRALIDADE DURANTE O ANO DE 1884
}

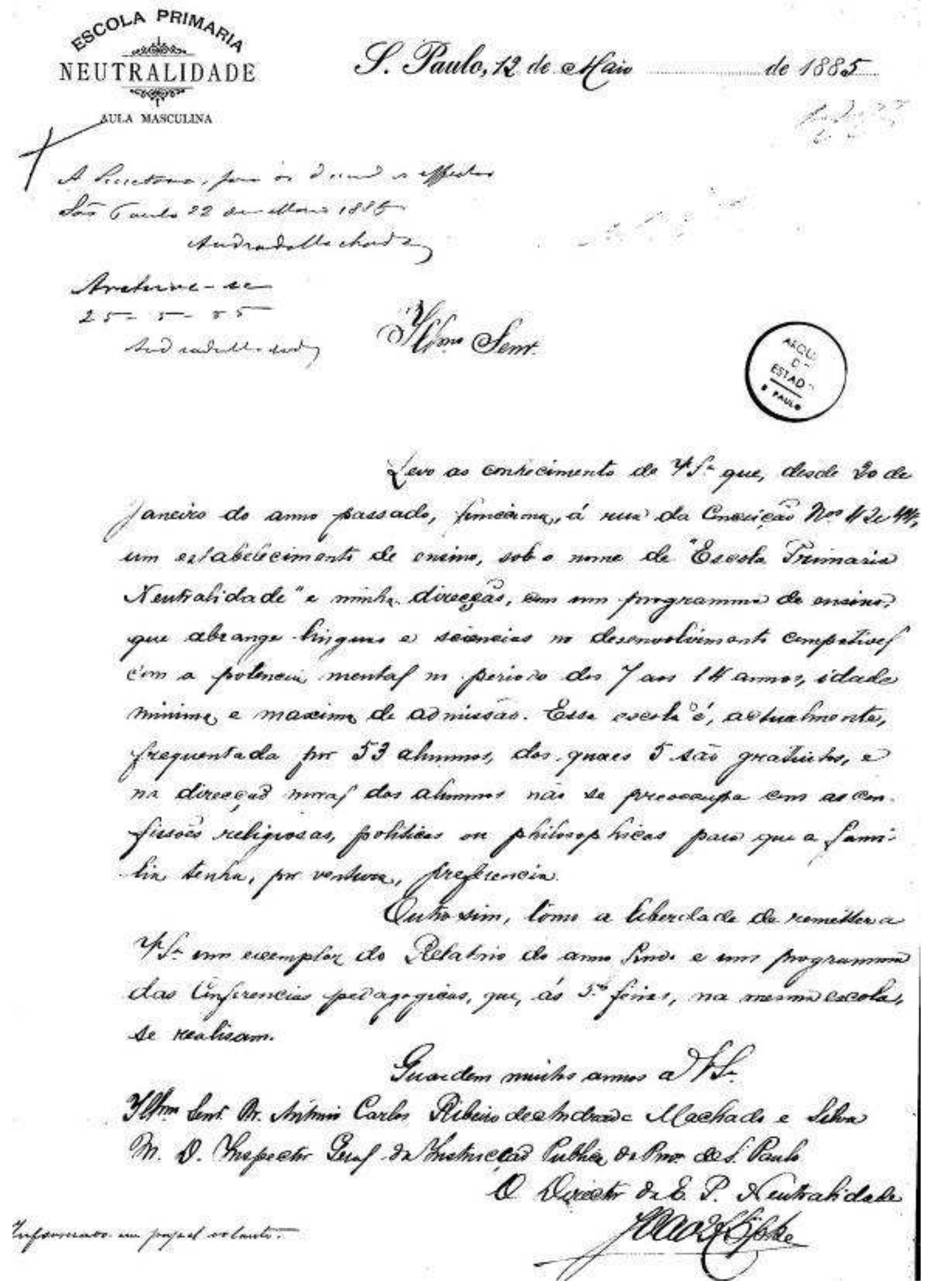


Revista HISTEDBR On-line

Documento

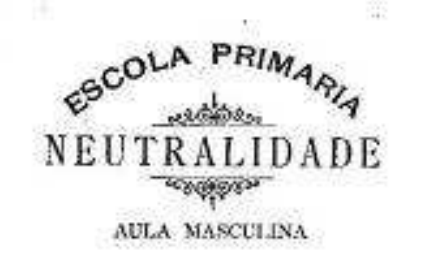

S. Prutbis, de

de 188

trorpo deconte

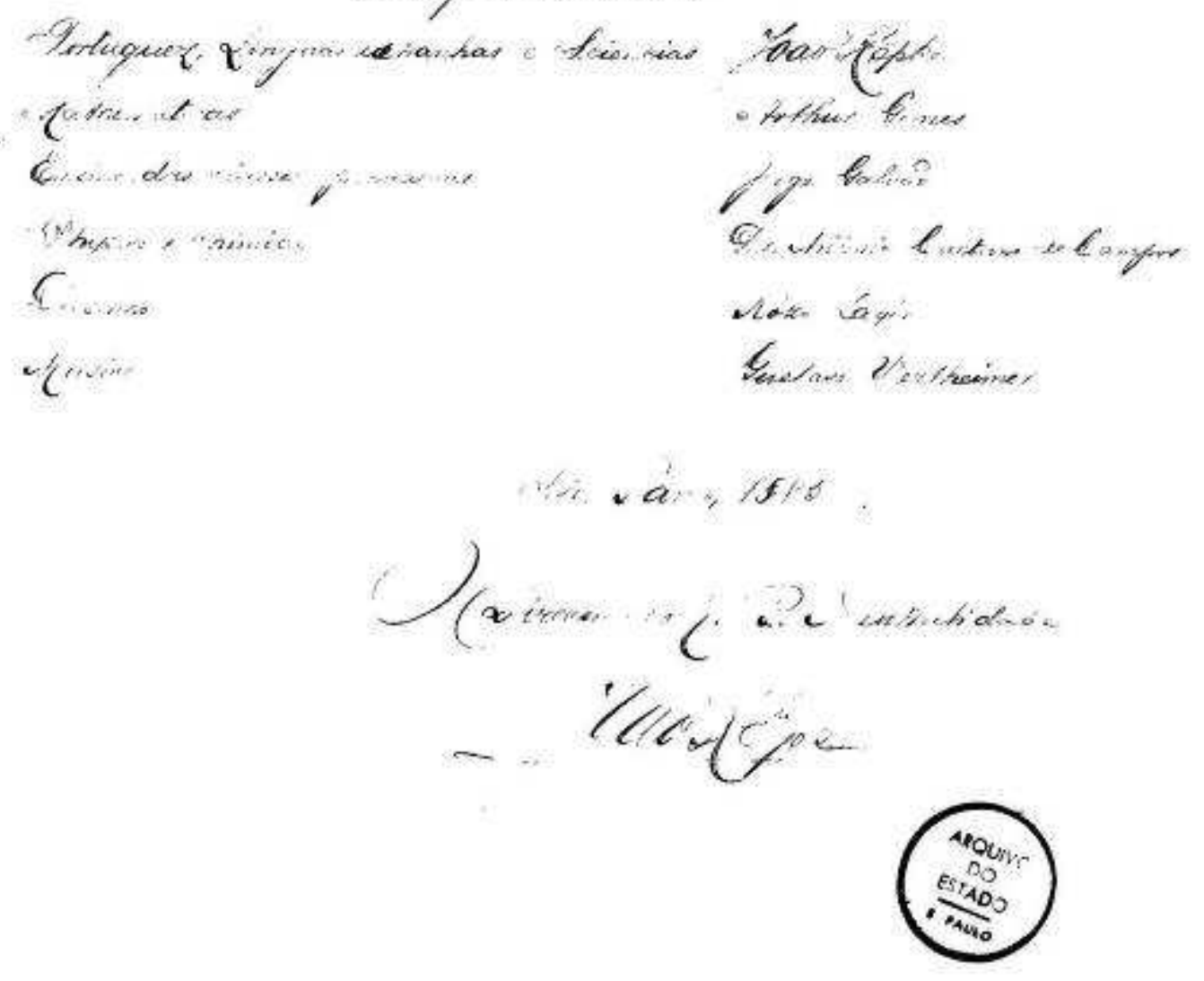

Revista HISTEDBR On-line, Campinas, n.35, p. 278-306, set.2009 - ISSN: 1676-2584

279 


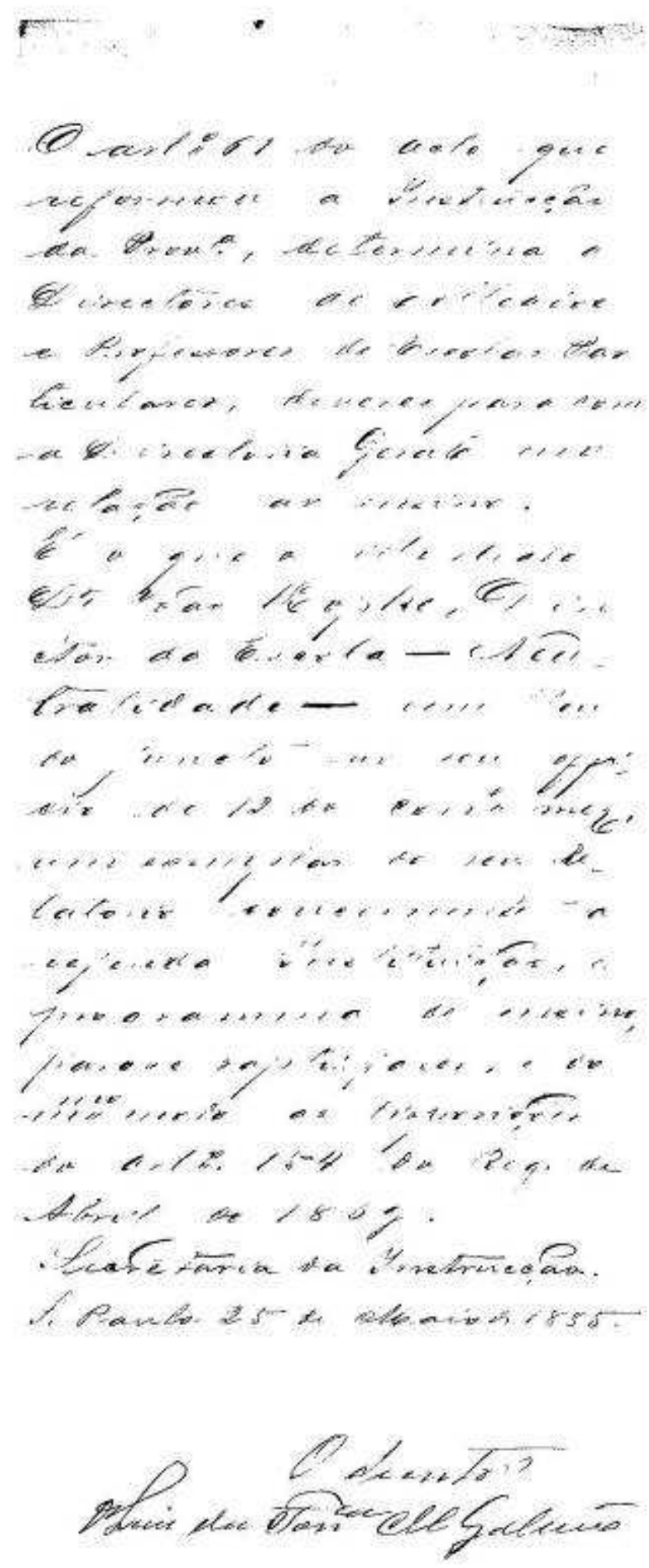




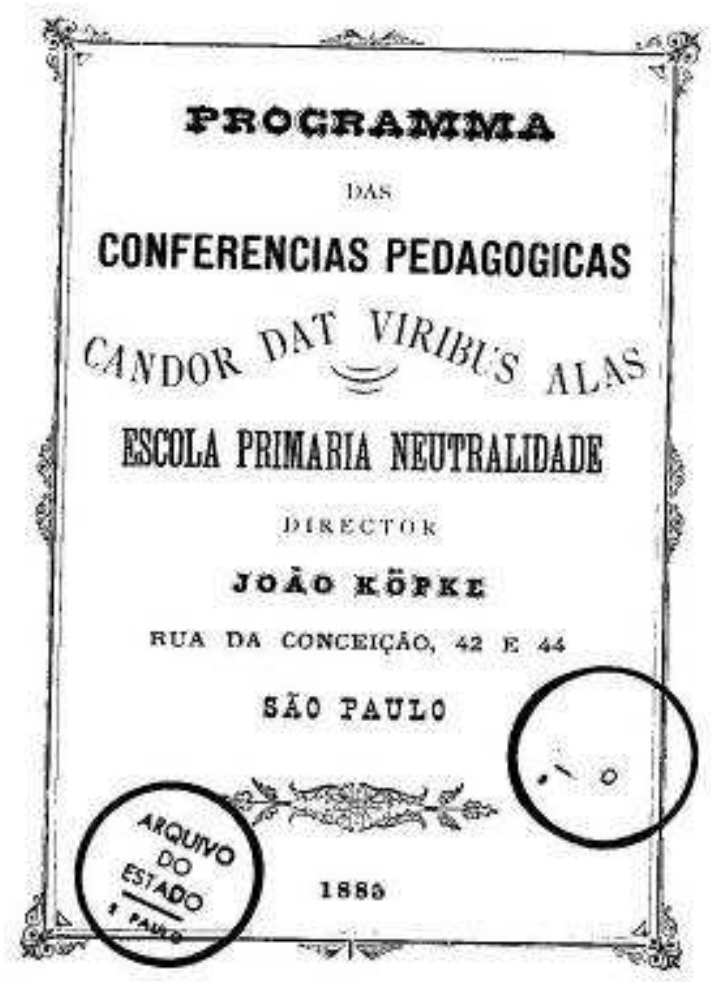



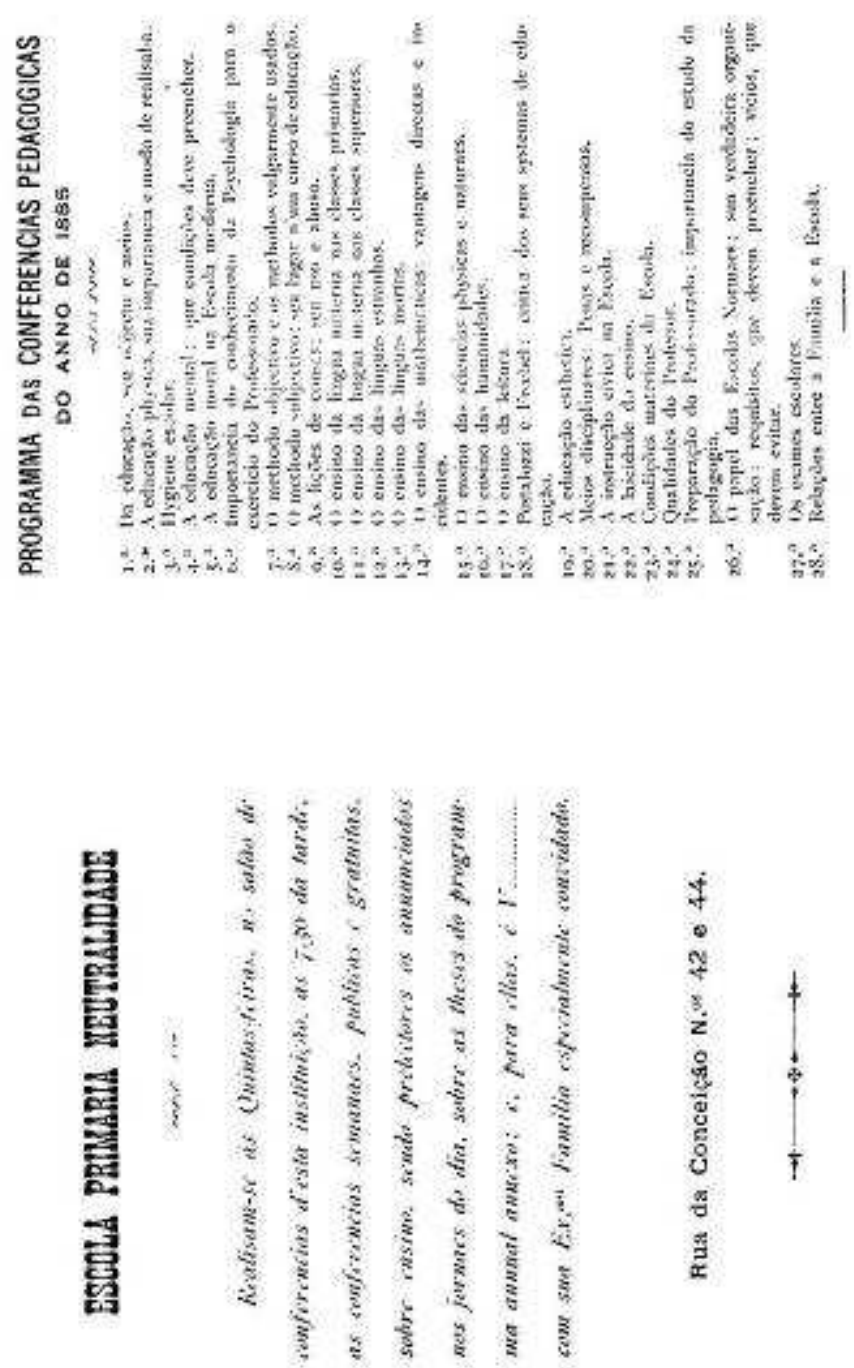


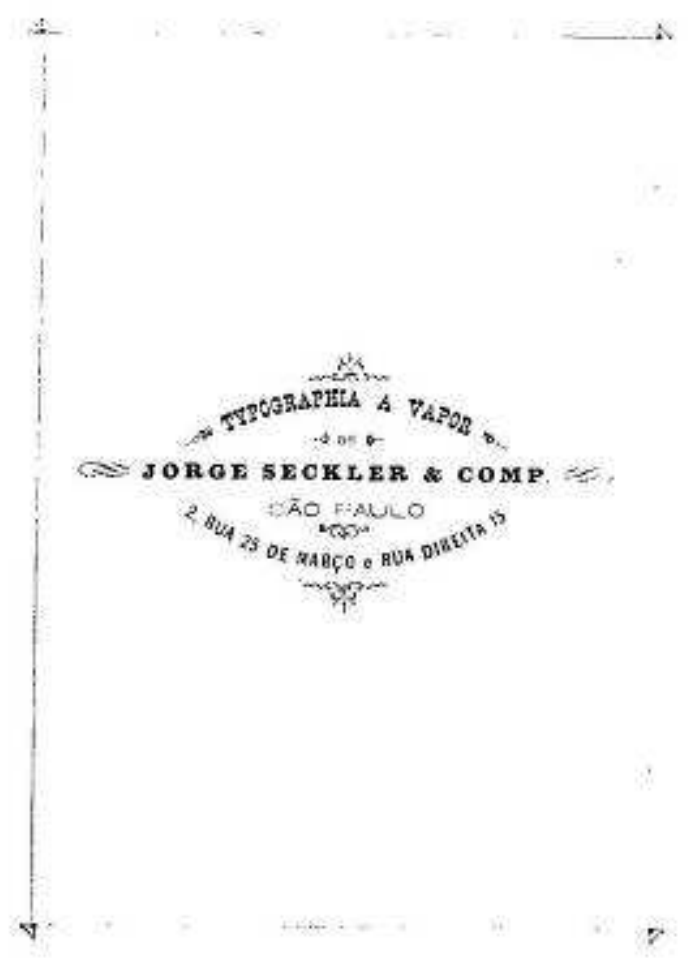




\section{SCOLA PRIM/A///}

NEUTRALIDADE

कesegsis

AUtA MascultiNa
P. Puulo, de. de $188^{\circ}$

\section{Relaciáo dos alumnos matriculados.}

\section{Doomes}

\section{Inliação}

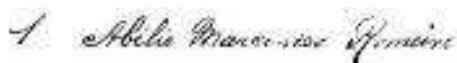

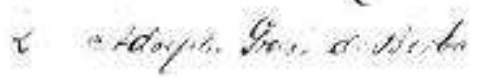

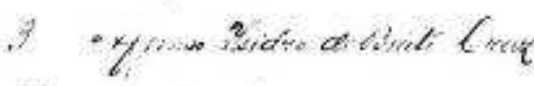

\& extin.

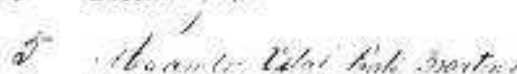

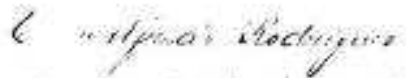

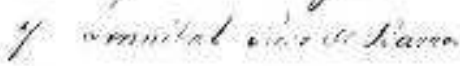

f

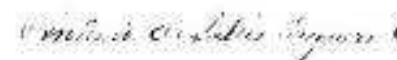

4 ctirser liaken

16 mpartianes

If Bntintwed

12 tewar byea

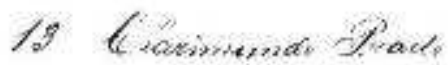

11. Caxio tmisate

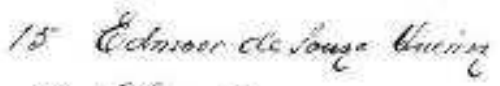

16 Ehad diyen

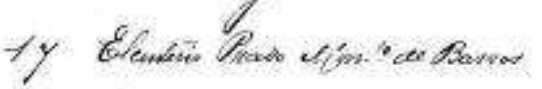

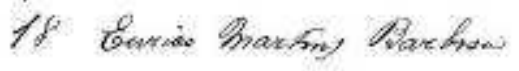

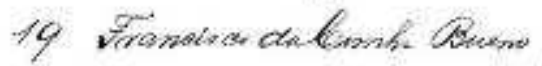

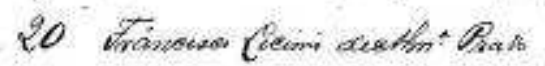

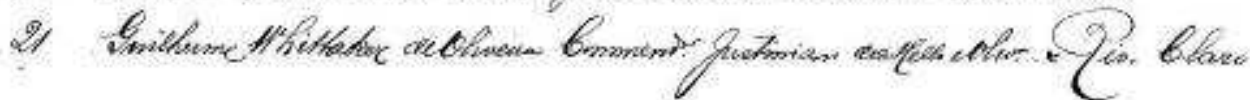

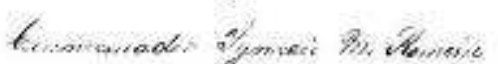

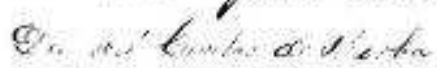

Residencia dos jaes

Tindementaned ta

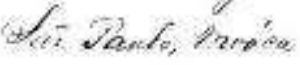

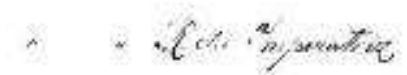

- $\operatorname{lin} 6$

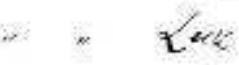

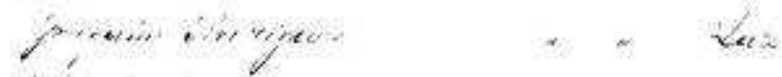

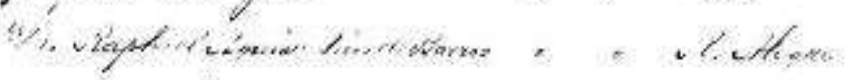

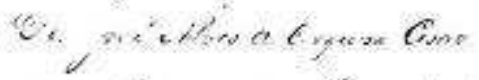

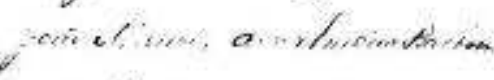

tameinas.

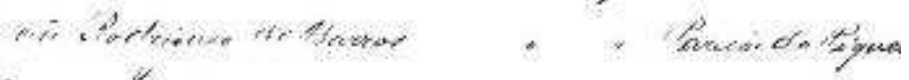

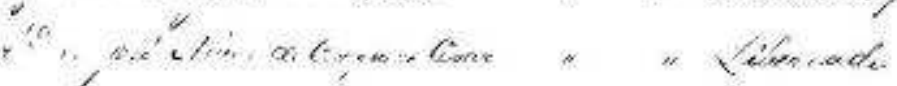

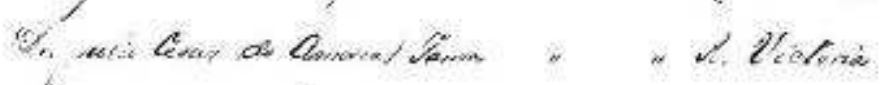

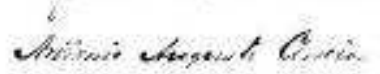

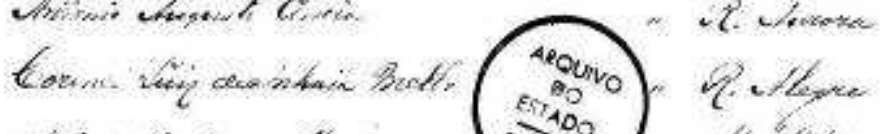

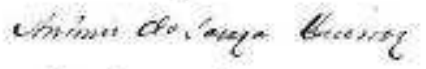

thospleno dleyer

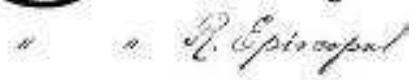

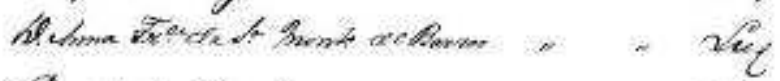

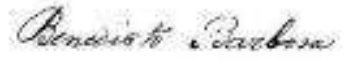

-2 Mlegar

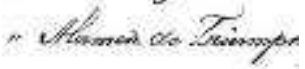

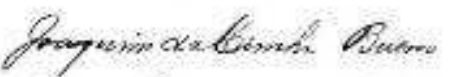

a

Qheos 
Revista HISTEDBR On-line

Documento

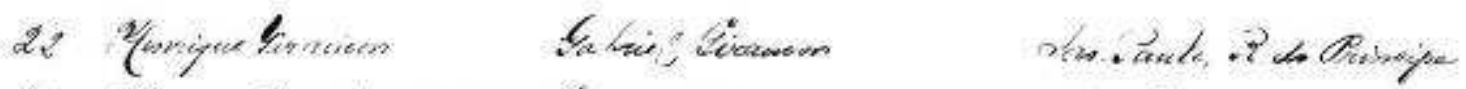

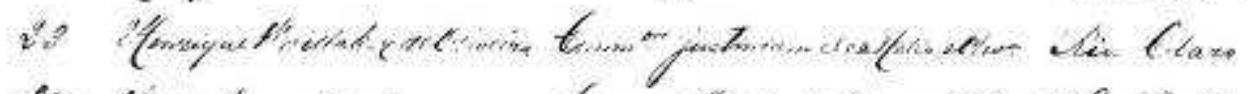

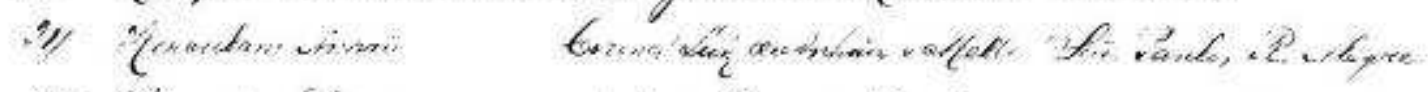

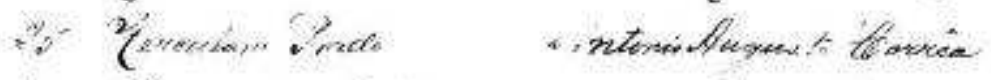

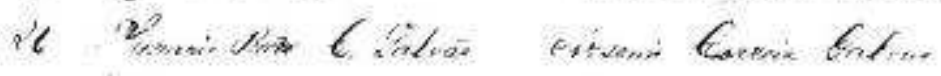

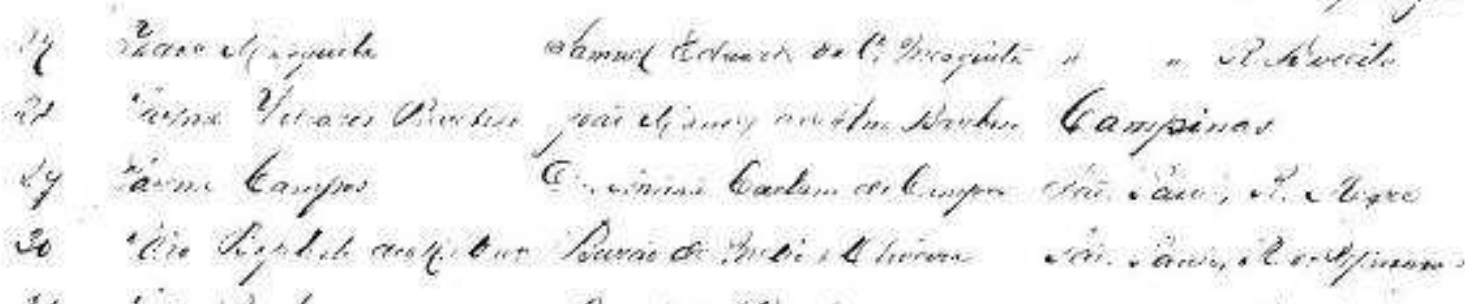

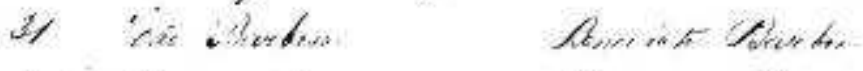

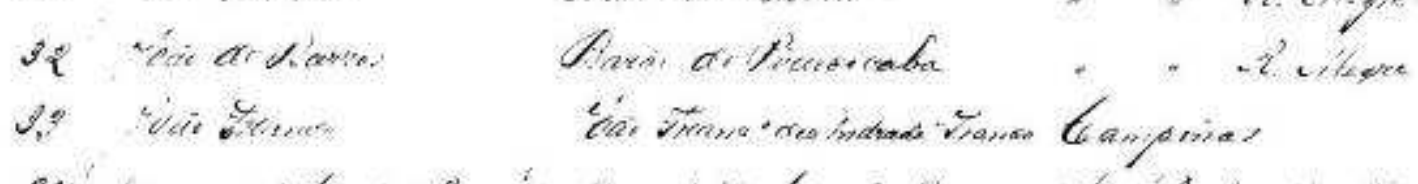

12. e.tyone

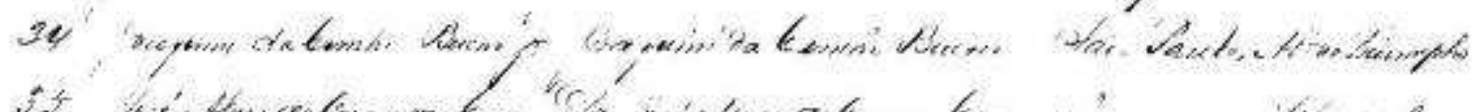

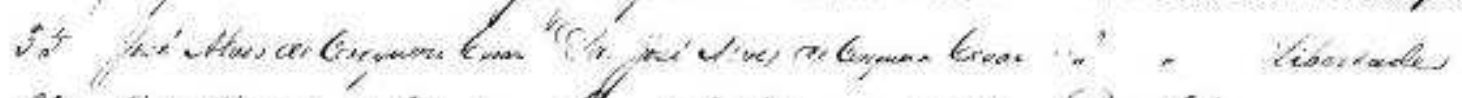

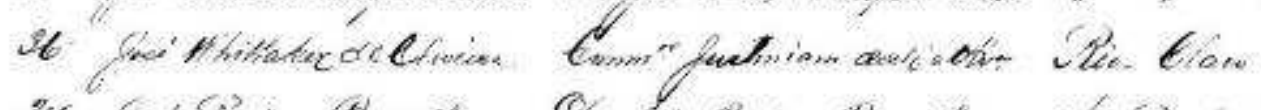

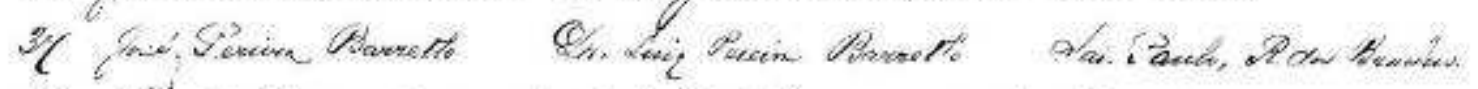

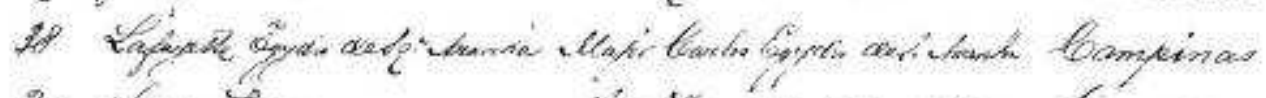

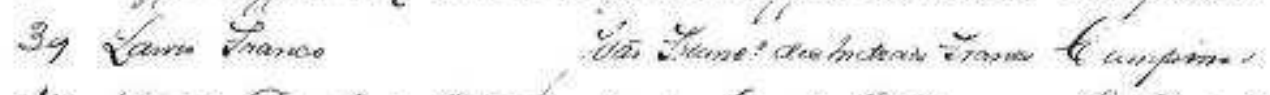

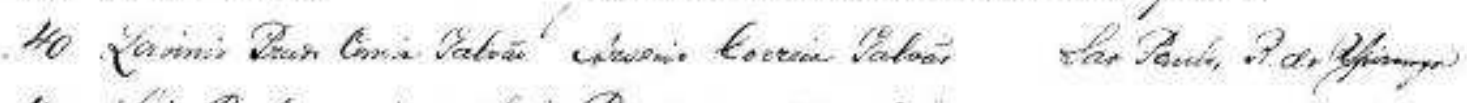

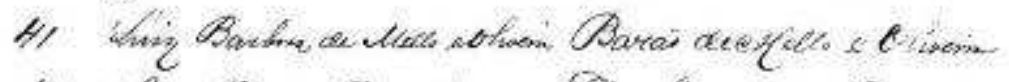

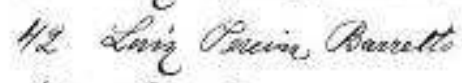

Q7. Disic Presin Tammedte

- Pas Panodios

4.3. सhiz Campoin

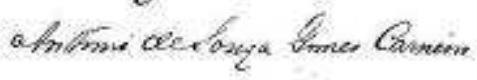

- Cospention.

Revista HISTEDBR On-line, Campinas, n.35, p. 278-306, set.2009 - ISSN: 1676-2584

285 


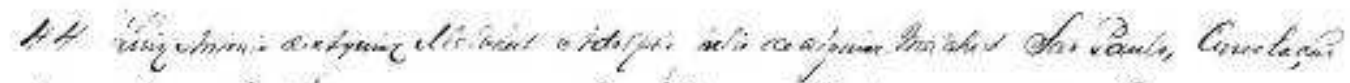

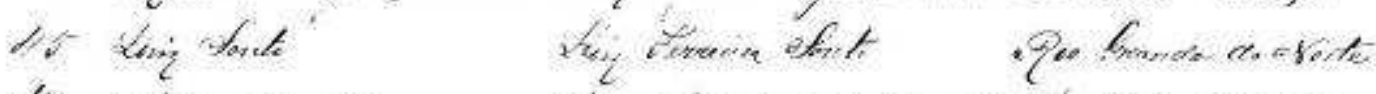

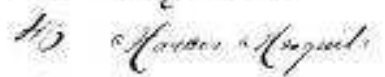

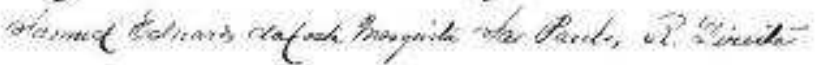

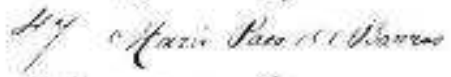

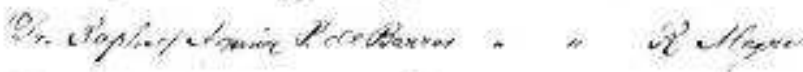

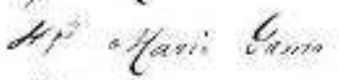

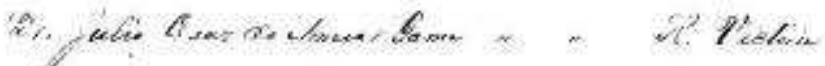

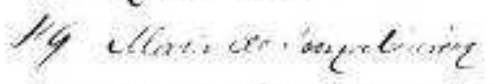

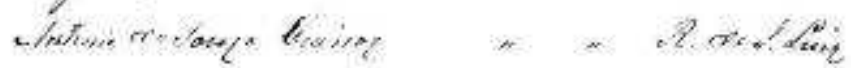

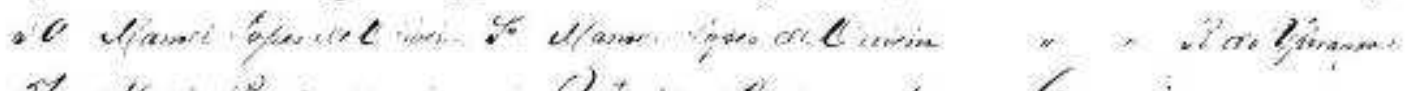

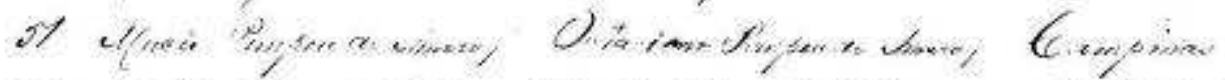

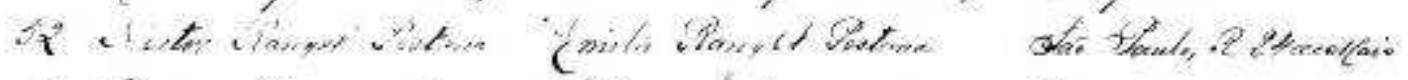

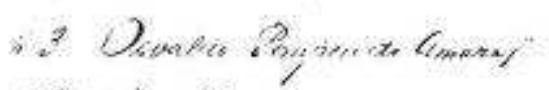

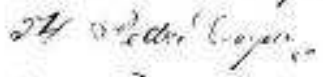

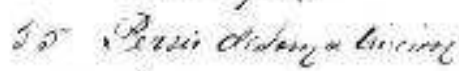

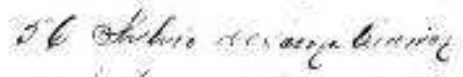

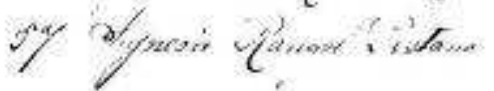

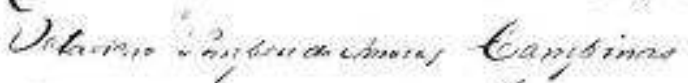

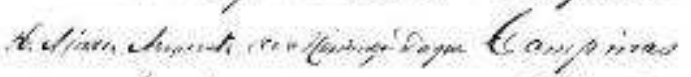

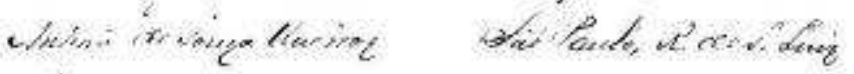

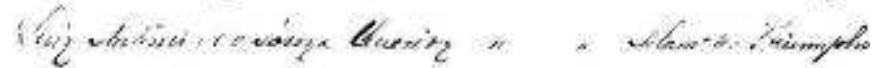

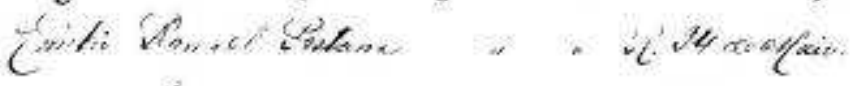

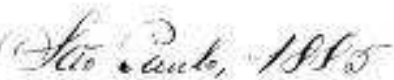

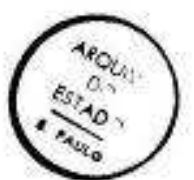

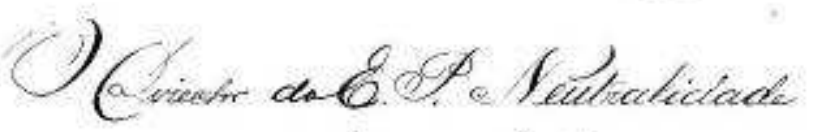

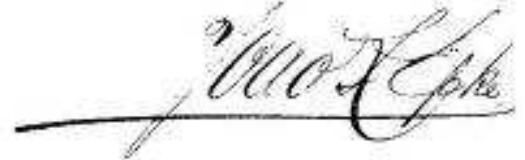

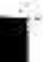




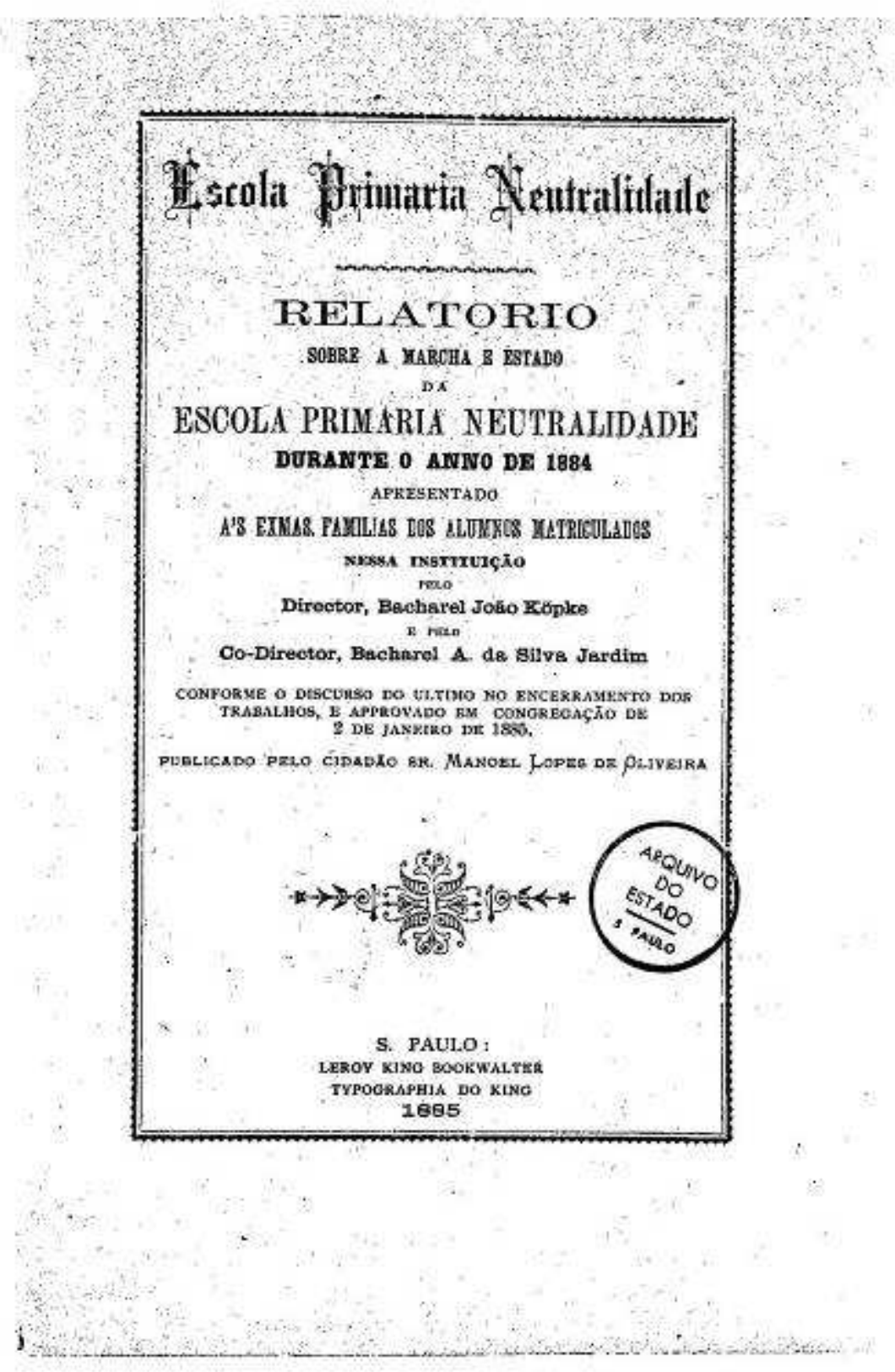




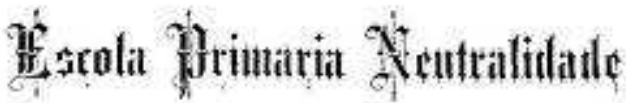

TELATORIO

SOBRE A MARCHA E ESIADO

Dix

ESCOLA PRTMIRLA NEOTRALIDADE

DURANTE O ANNO DE 1884

AEkPastimo

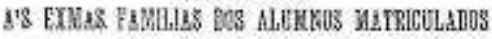

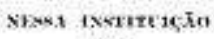

Director, Bncharel Joho Kopploc

Co-Directot, Bacherel A da silvs Jardim

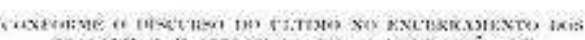

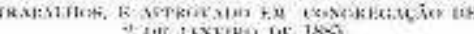

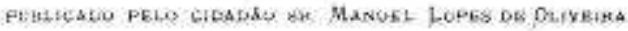




\section{RELATORIO}

$n a$

\section{GSCOLA PBIHARIL NEUTRALIDADR}

A's EXXıS. FAMILIAS.

A pos os resultiudos praticos que do seu ensitso en par-

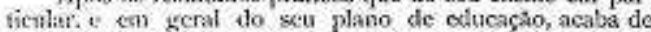

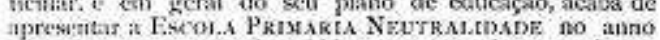
cue fibda, tho parece desculyida a marraçáo de seus esforços

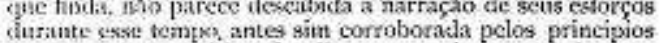
ciurinte sisst temps, antes sint corroborada pelos principios

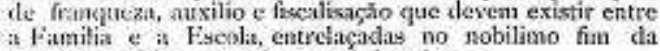

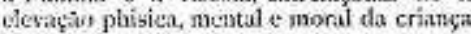

1

Puntar de fid molo prendem-se arui os acontecimen.

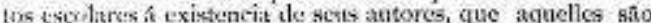
umit resistante desta, destu entío carecediora de rapido, mas unctise talsure.

Formado em Sciencias Jurúlicus e Sociaes pela nossa

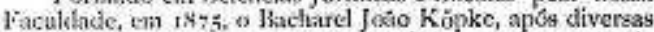

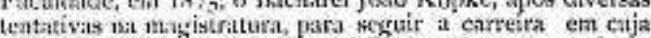
aspirancia tanto tcuyo gastara, deliberou abraçar a protissáo de «es l'ai, o funcludor do Colkgrio Köplec, em Petropolis, a şu:sl sm épocas academicas exercera por necessidade c gristo.

i) wisules an magisterio particular nesta cidade e na de

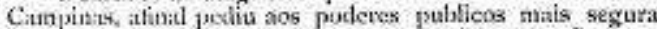
sulvesterucia ubinendo, por concusso, a cadcira de Geogra-

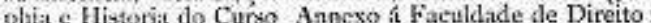
as ts nas tsquecido de stia nelhor tuadencia, o ensino pri- 

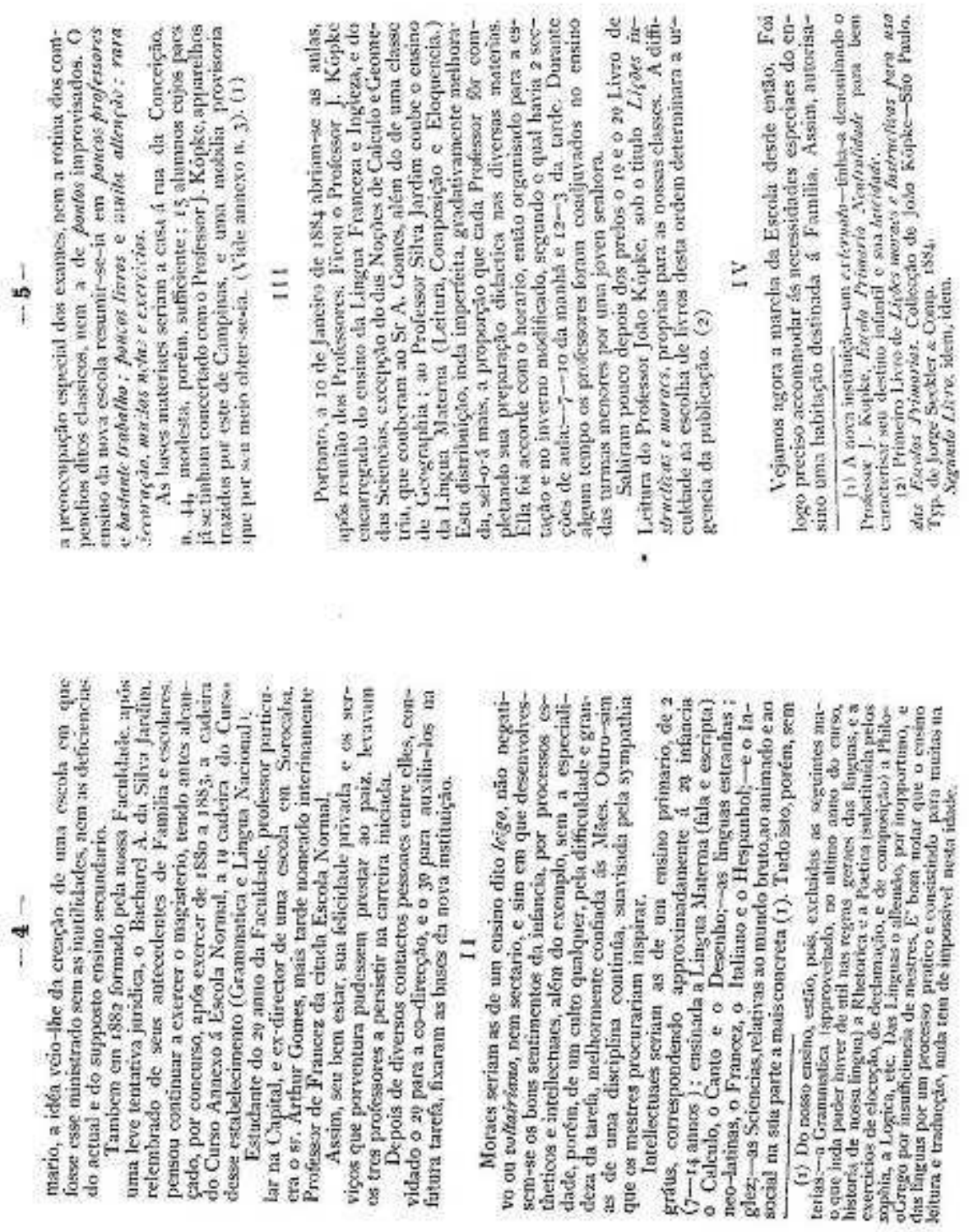

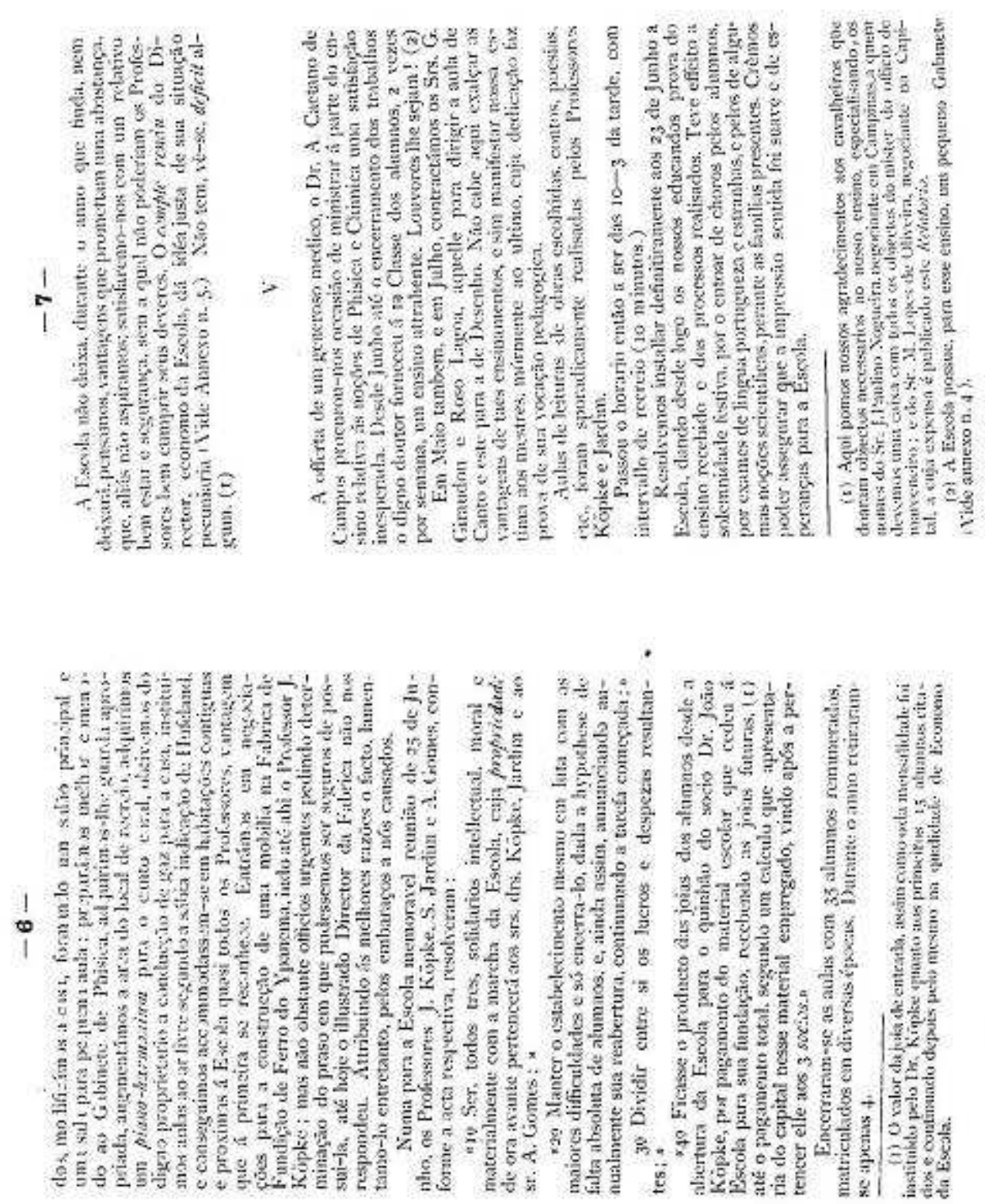

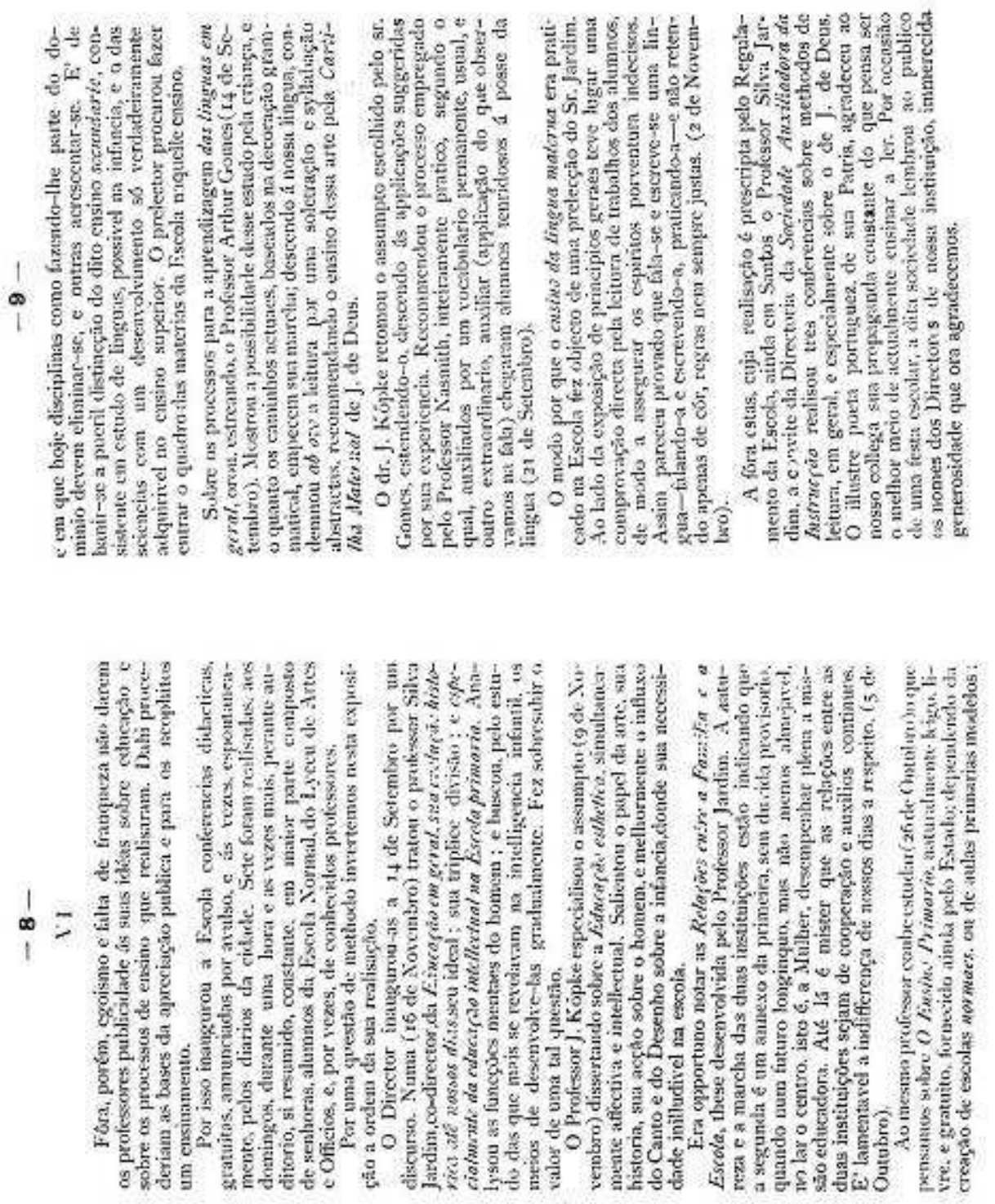

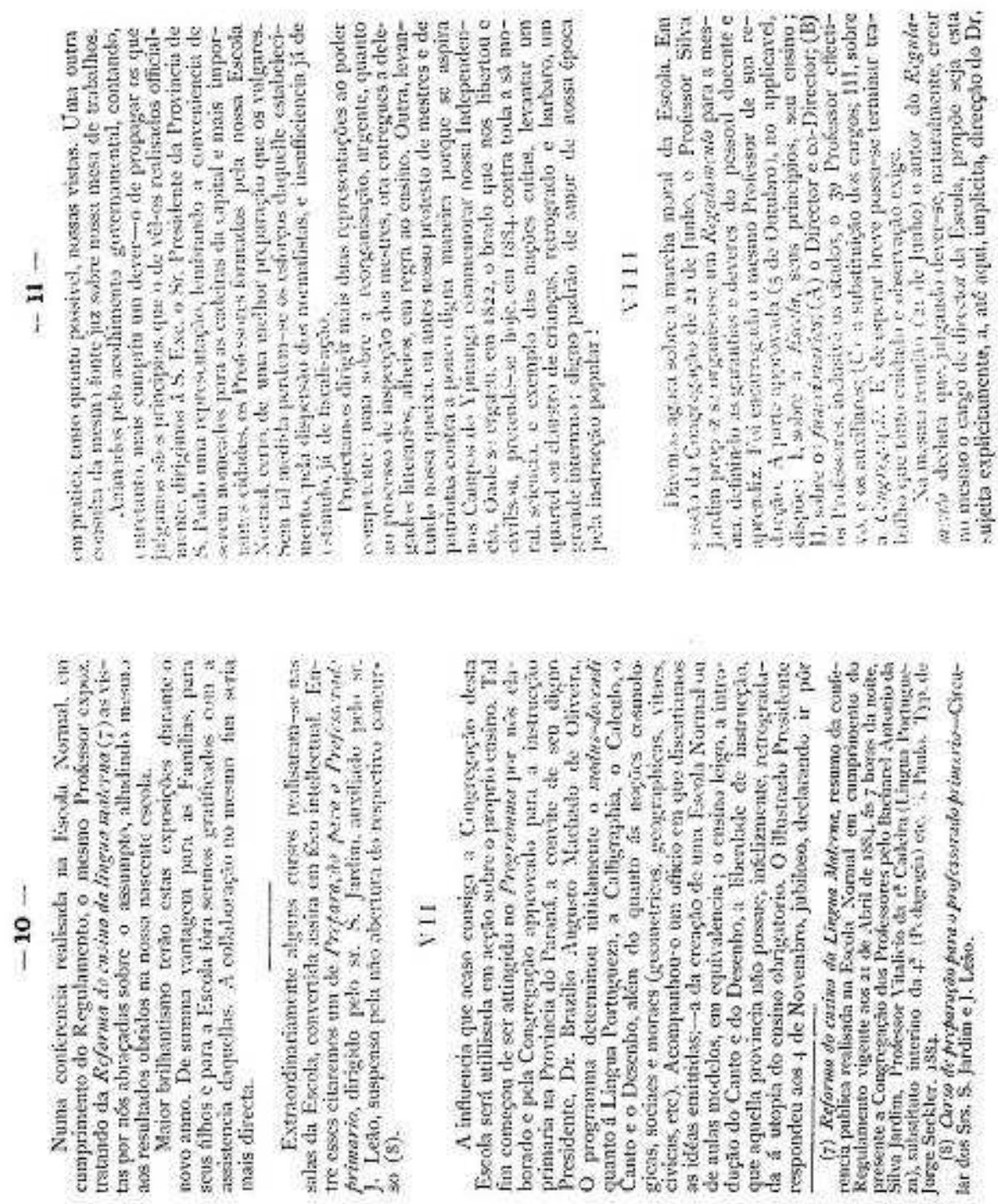

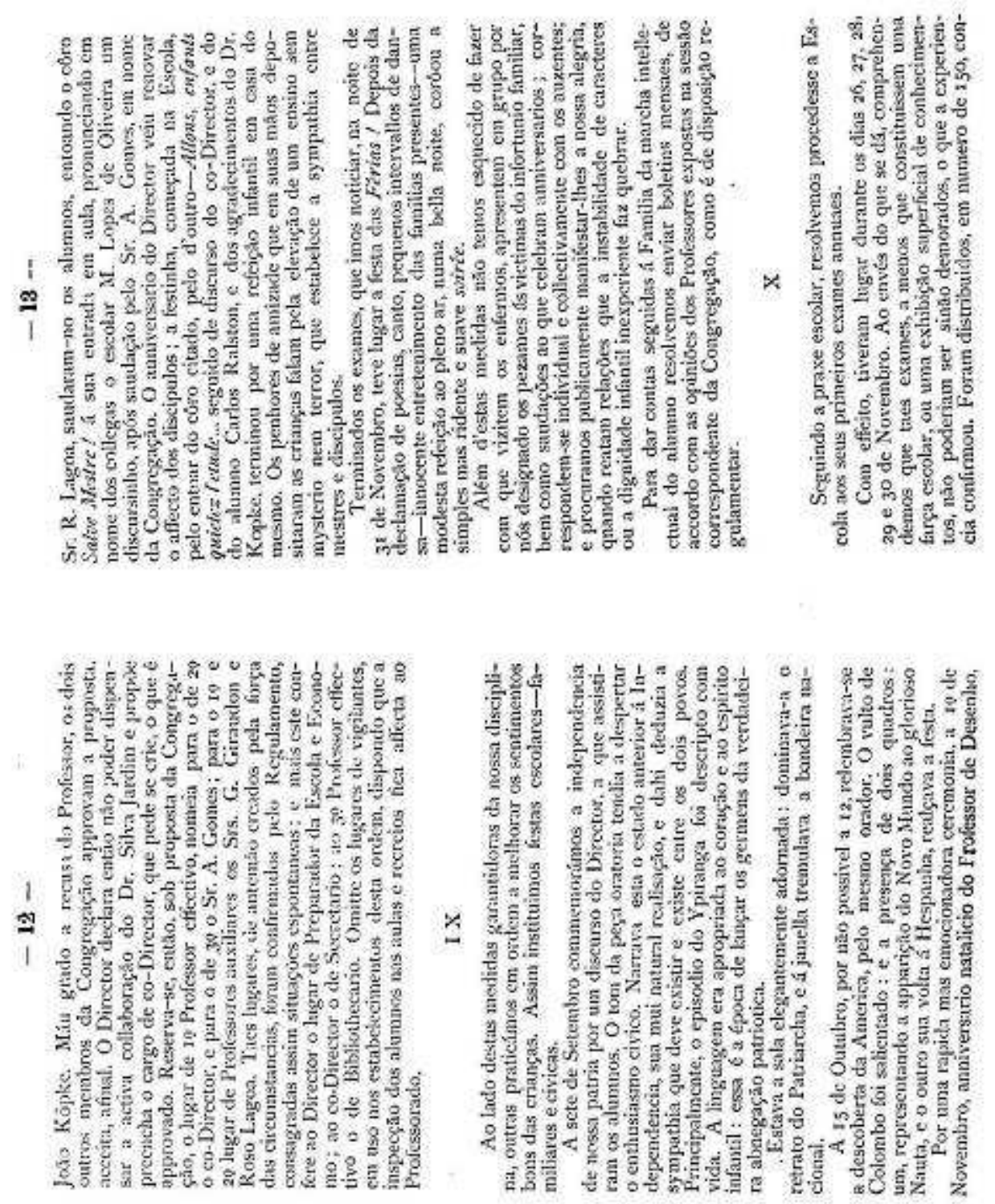

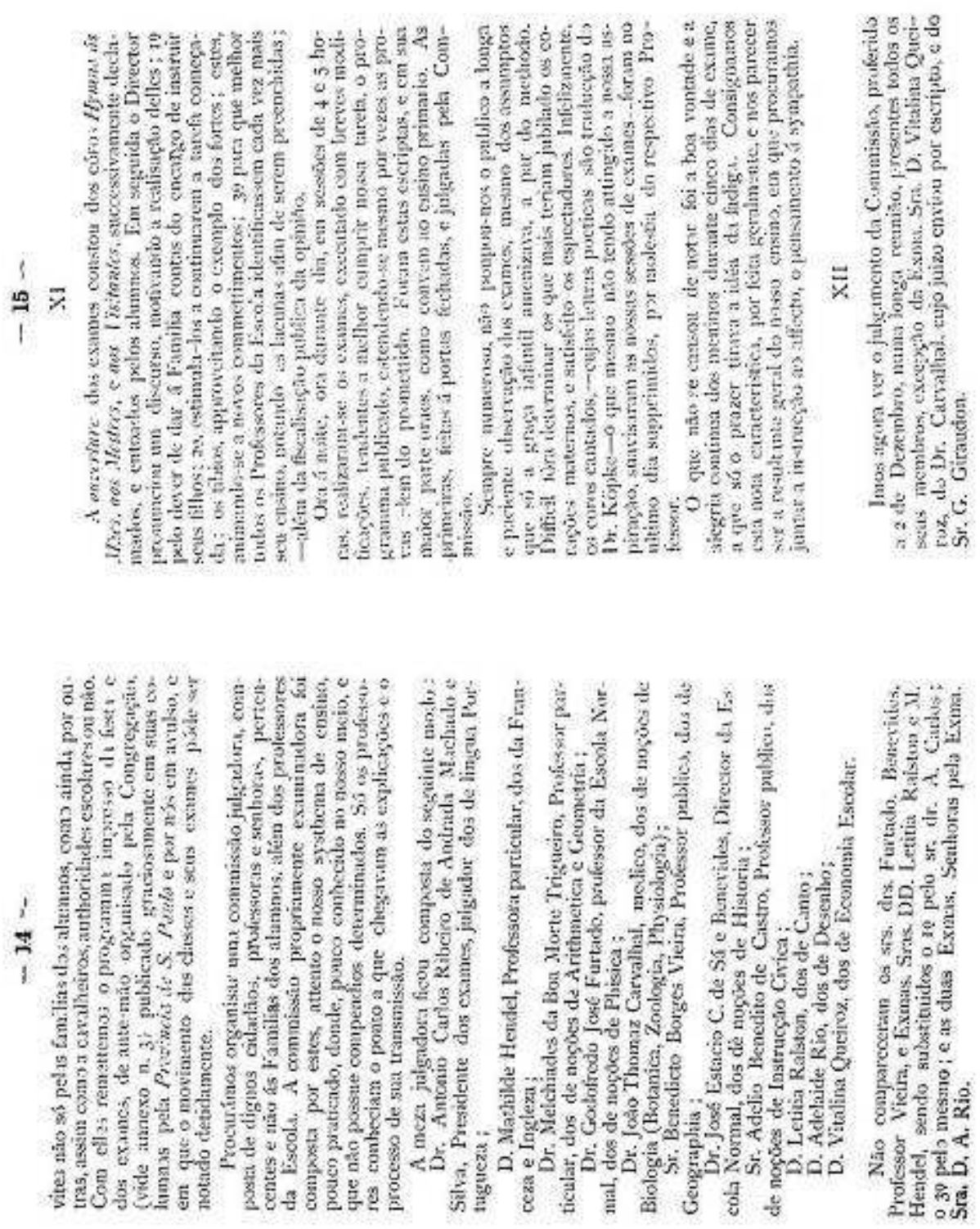

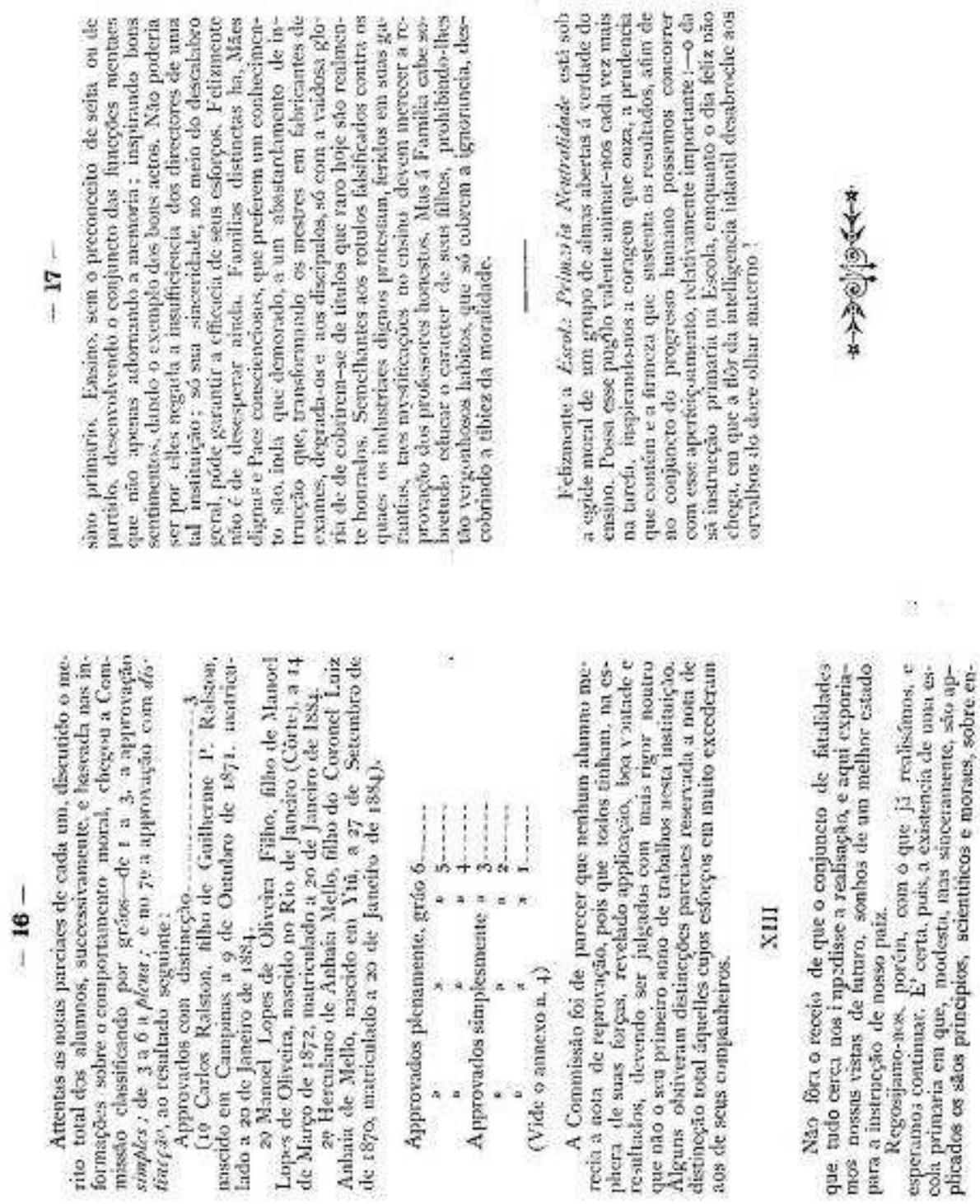


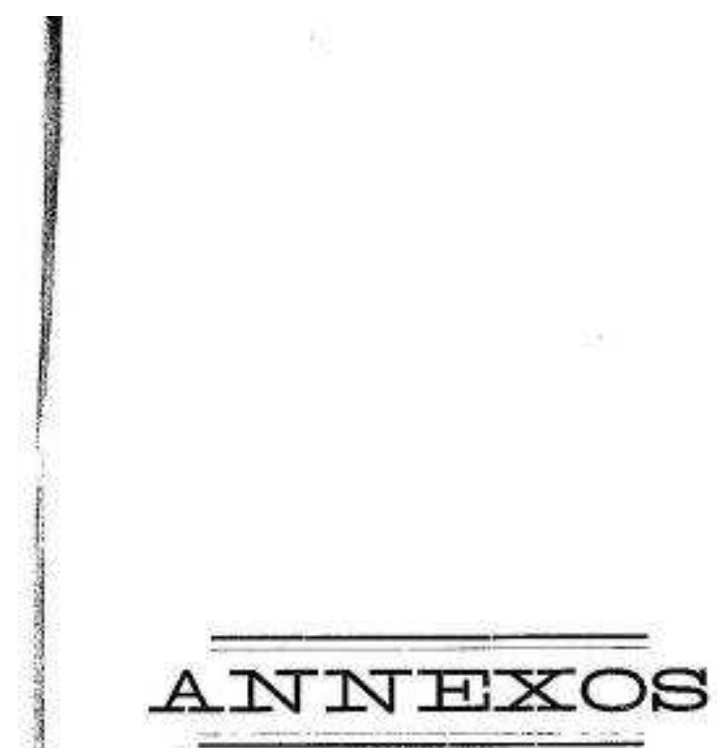


A. INTT2xO IN. 1

\section{CORPO DOCENTE}

JOÃ KOPKE

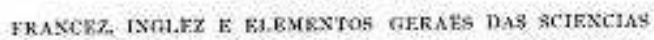

BACHAREI. ANTONIO DA SIIYA JARDIM

ATRGUA PORTUETEZS

ARTHUR GOMES

MATHEMTATCAS E GEOGRAPHL

ROSO LAGOA

DESENHO

GARRIEI. GIRAUDON

MUsic vocAs.

DR, ANTONIO CAETANO DE CAMPOS

PHVSICA E CHINICA 
A ININEXO IN. 2

\section{CORPO DOCENDO}

Abilio Mascunuies Rumeire,

Ailio

As

Alexandre l'sinto Martions.

Alfreclo Rodrigues.

Annilast Barros,

Girlos Ralistum.

Dario Anhaia.

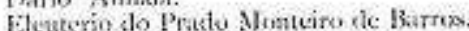

Fincisess tha Cunlat Buenos.

Gisiofredo Hlerculieno.

Henrique Giraudon.

Herculans inhitia.

Igracio Prado Corrét Galuàn

Mac Mesquit:

jume Burbosa

fiverse Cimpos.

Jixlo Baptistit de Mello e Oliveira.

kean de Bawros

Joth France.

Joseviom ata Coutha Bactes.

Lafiyette Eysalio de Souxit Aranha.

Jituio Franco.

Luix Barbroa de Alelio e Oliverta

Luiz Melchers.

Laiz Souts.

Vanod lopes sle Oliveirat Fitho.

Marcons Mesquitit.

IIario Barroy.

Vario Queiros.

Streice P'ompers do Amirat

C)swablo L'anyess de Amariol

Pevelres pounac.

Persio Quiros.

Sylvis Otreiroz.

Thiago Ramalho,

Mistriculou-se, e retirno-xe communicando:

Edimundo Rotrigues Jurcino.

A:atricularamse e rctiraram-se sem conmunicagáo alguma:

Joacuin Moraes.

Sebastian Aloracs.

Matriculon-se e náo frequentou:

Joho Albetto Junior. 


\title{
MATERIAL DE ENSINO
}

\author{
ABINETE DE PHYSICA
}

suçös Geraks

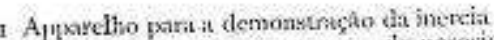

" dit porosidistk.

2 Placis te colvesiñs.

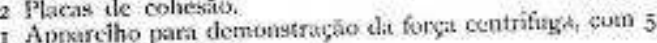

- Apcis accessórias

1 dito, ditu, sito, sinup̧les.

IBARULOTHA

I Fo de prome

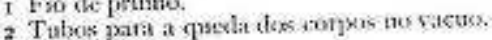

i. Martedlodinguis.

- Apuarellas para demonstrar a pressas dos liquifos de likiso parti cims.

1. Dito ditu dito dito dito en todos as sentidos.

1. Torniçacte hyclritulios.

Finseo de deabidictes.

Series de vates crimmuricantes.

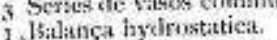

1. 15:alinģa byclenstaticit.

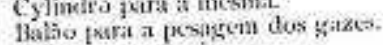

1 Jrickset panamintios.

2 Tubos de Tirricelli com cuhi.

Baronetor de siphăes.

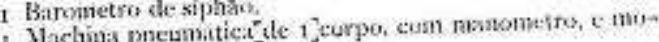
vinentes be alivancis

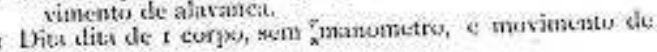
seringa.

1. Campanula. 

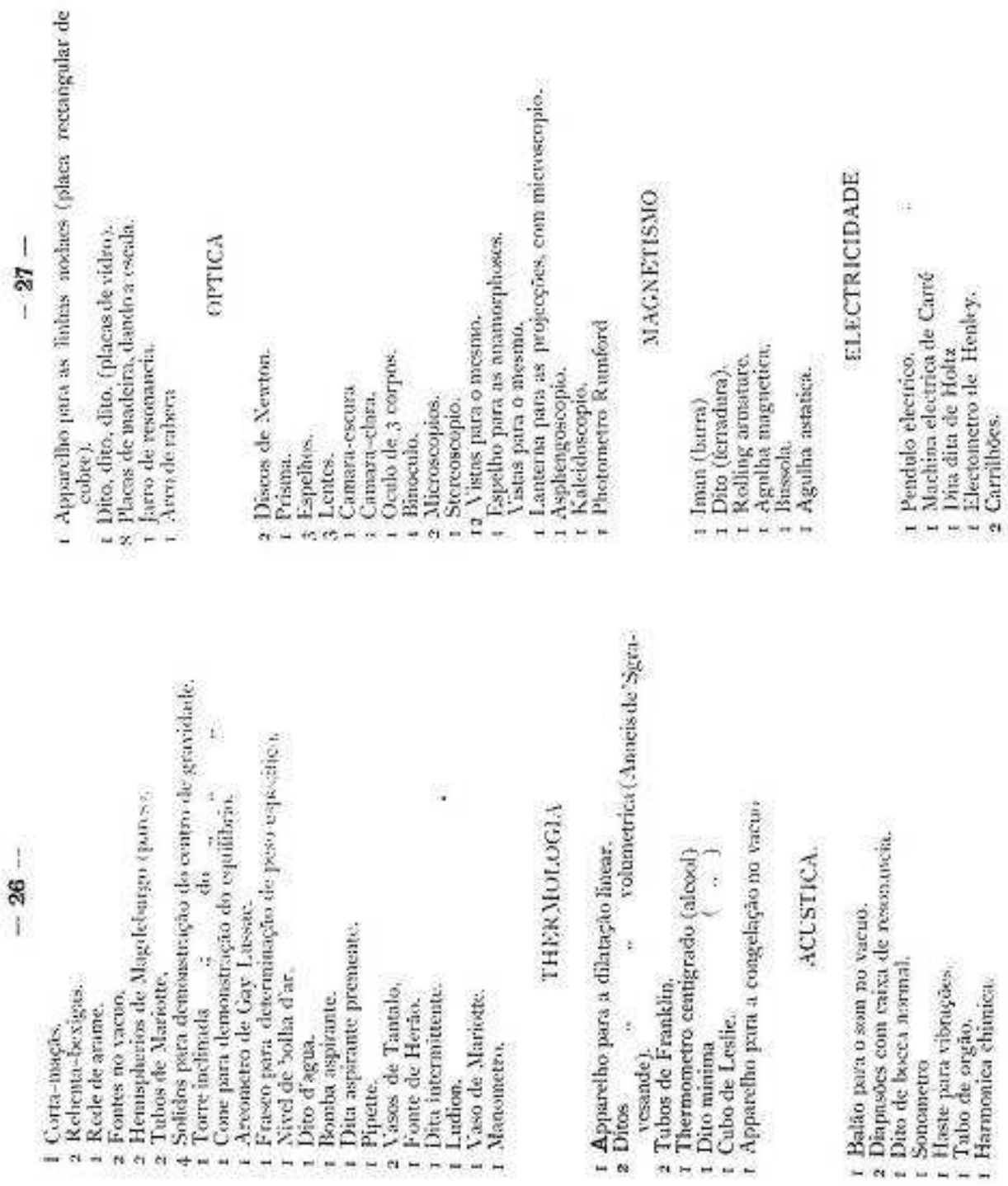

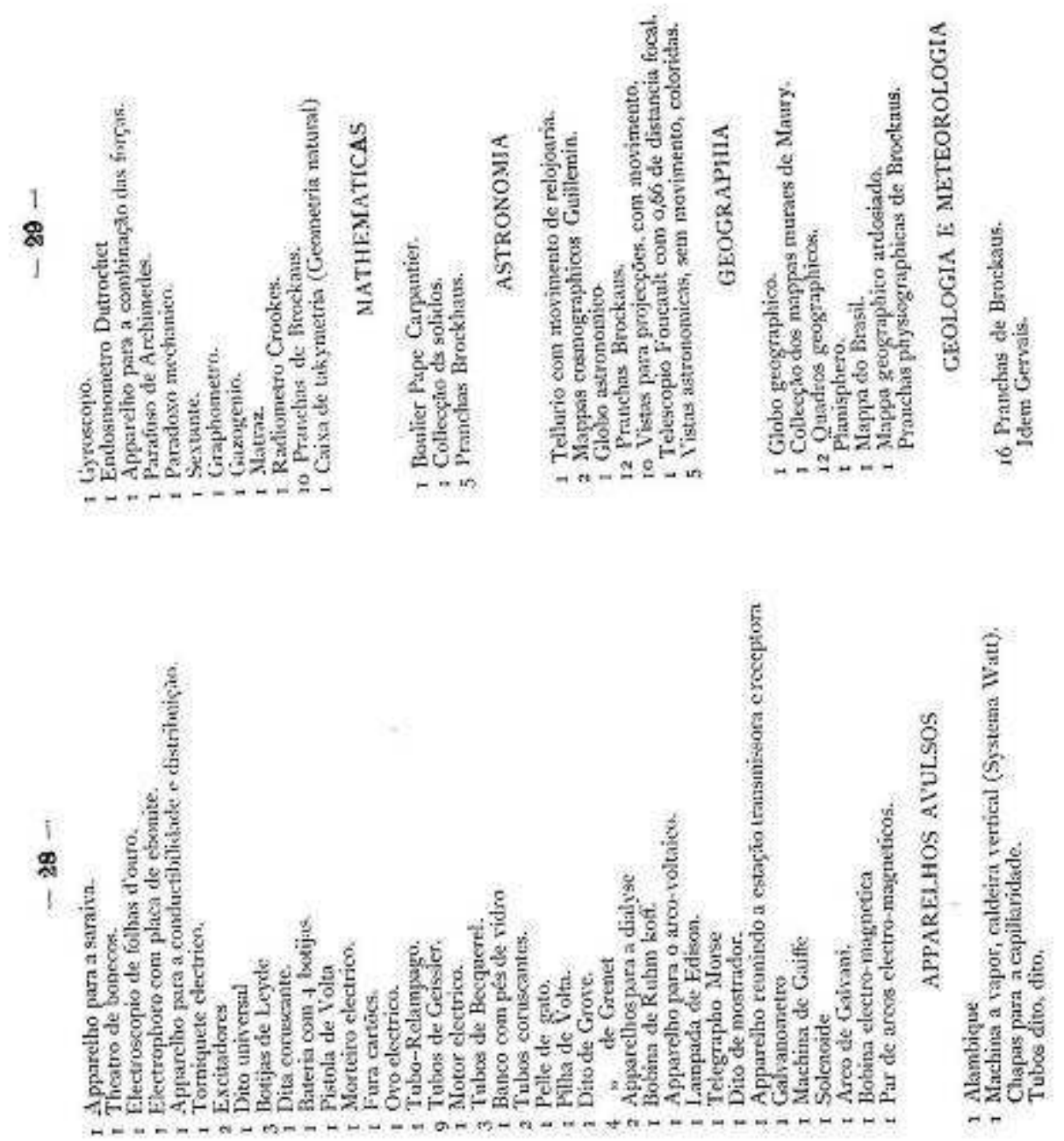

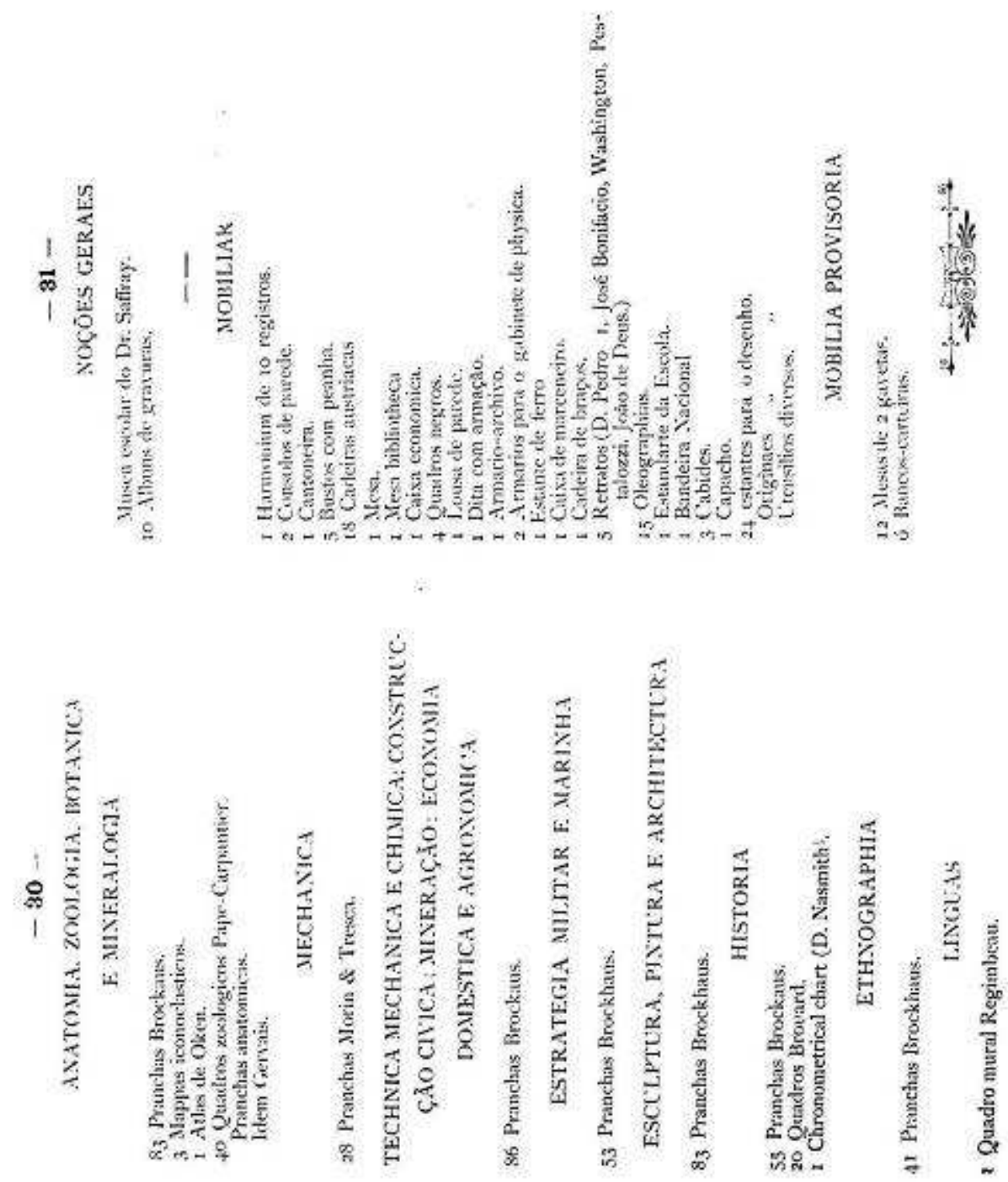
A.N2T FX20 № 4

PFOERAMVA DOS PRIKPIROS BXAMLS ANSUAFS

APPROYADO IKM CONGRTSBACA,

tor

23 DE NOVHMAPO ID 1894

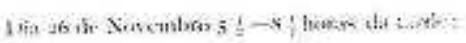

$$
\text { 2) } \rightarrow x k r:
$$

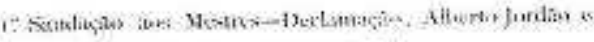

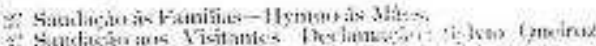
inis.

$2100 \times 10$

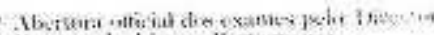

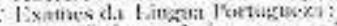

$12 \sin x+x$

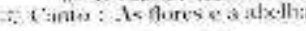

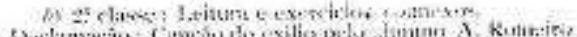

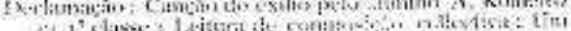

काषाk.

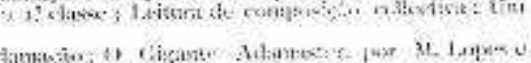

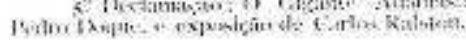

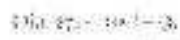

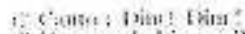

(1)

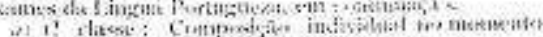

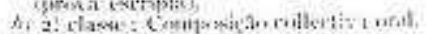

Q. I astis: (1) moinhe

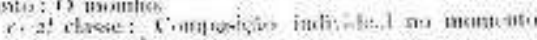
prevatesisplis

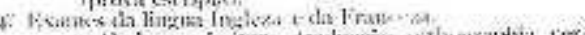

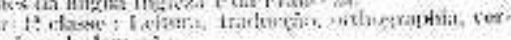
(m)

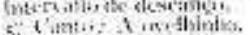



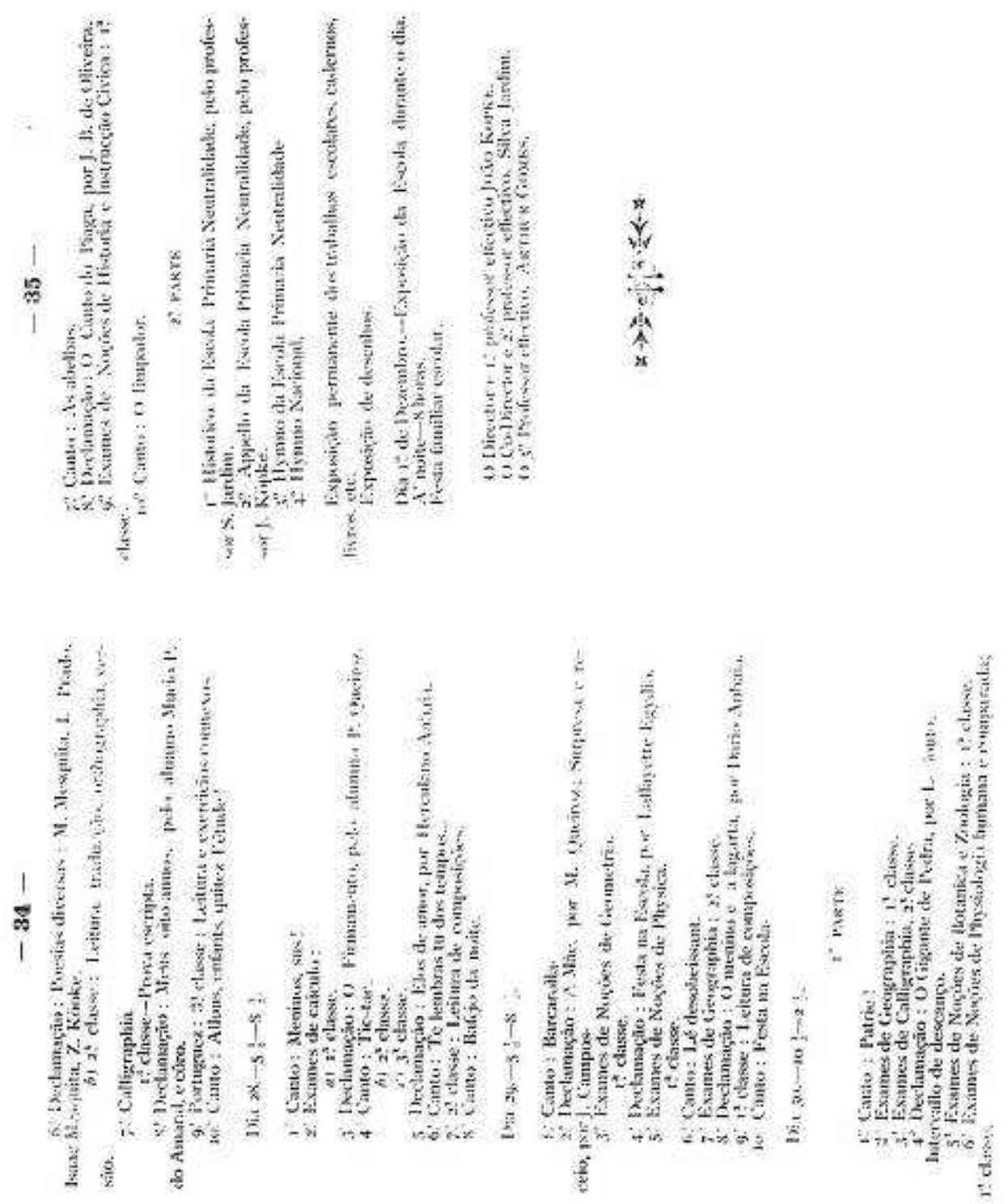


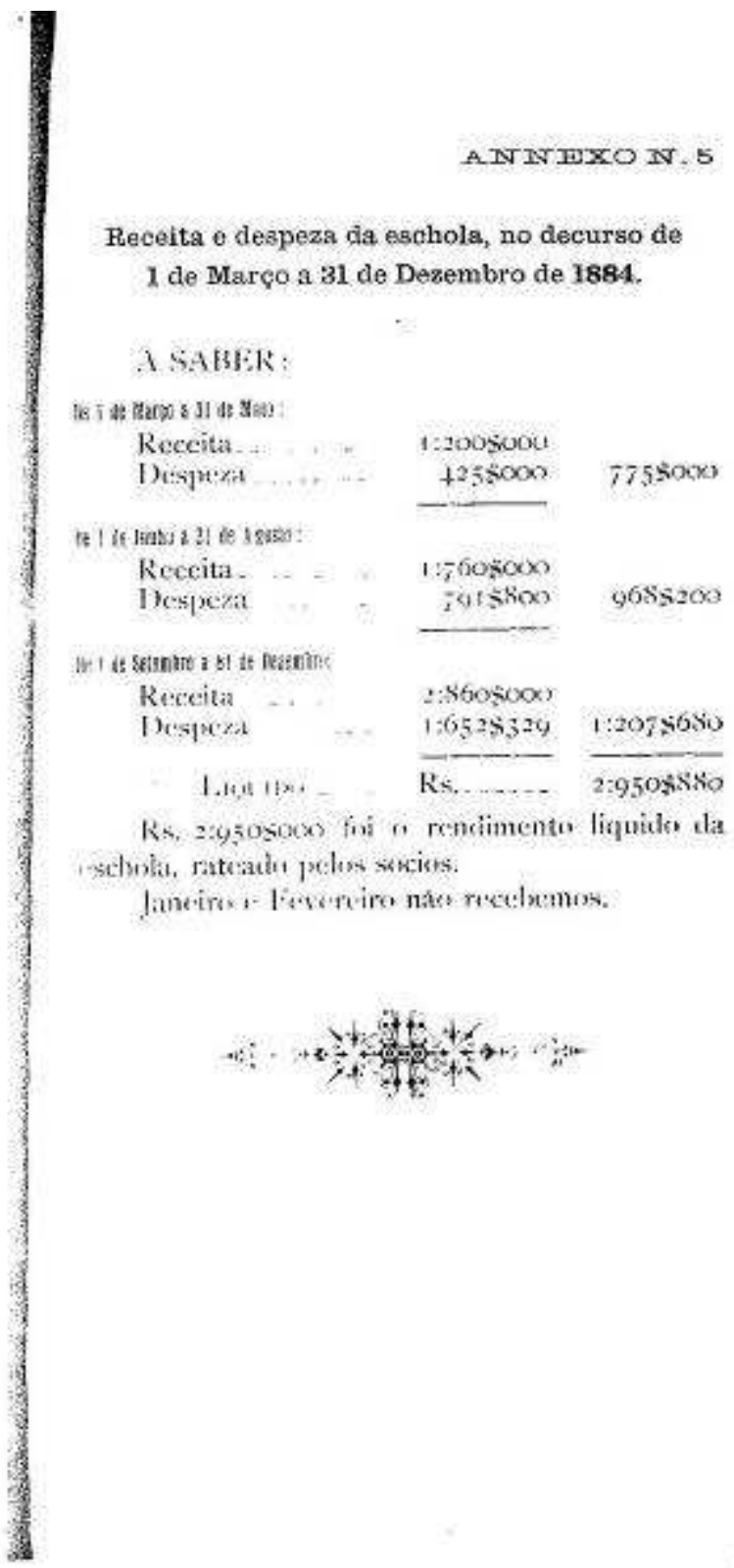

